\title{
STUDY OF HEMATOLOGICAL PARAMETERS AMONG NEONATES ADMITTED WITH NEONATAL JAUNDICE.
}

Dr. Amar Shah, Dr. C. K Shah, Dr. Venu Shah.
1. Assistant Professor, Department of Pathology, Pramukhswami Medical College, Karamsad, Anand, Gujrat.
2. Professor, Department of Pathology, Smt. NHL Medical College, Ahmedabad.
3. Assistant Professor, Department of Community Medicine, GCS Medical College, Ahmedabad.

\section{CORRESPONDING AUTHOR,}

Dr. Amar Shah,

Pramukhswami Medical College,

Karamsad, Anand, Gujarat,

E-mail: amarrshah@yahoo.com,

Ph: 09909927725.

ABSTRACT: INTRODUCTION: Jaundice is most common problem faced by neonates in the first week of life. Although physiological jaundice is more frequent as compared to pathological jaundice it is very important to differentiate between the two as pathological jaundice may lead to kernicterus and subsequently brain damage. There are various modalities of investigations e.g. Serum bilirubin, Direct and indirect coomb's test, Blood group, G-6PD deficiency, reticulocyte count by which we can reach at diagnosis. Treatment is also dependent upon the amount of serum bilirubin and various other laboratory investigations. Thus laboratory workup is very important for diagnosis and prevention of neonatal hyperbilirubinemia in newborn. With this background present study was conducted to study the clinico- pathological profile among infants with neonatal hyperbilirubinemia. METHODOLOGY: A prospective study was carried out for the duration of 1 year in one of the teaching hospitals. RESULTS: Altogether 63 babies were enrolled in the study. Male babies out numbered the female $(58.7 \%$ vs. 41.3\%).Mean age of the study population was 2.97 days with standard deviation of 1.2 days. Percentage of Pre-term babies was 30.1. Neonates having low birth weight were 17(26.9\%). Physiological jaundice constituted $(40) 62 \%$ cases of Neonatal hyperbilirubinemia. ABO incompatibility was the commonest cause of pathological jaundice followed by septicemia. Statistically significant rise in the serum bilirubin was noted in pathological jaundice as compared to physiological jaundice. C-reactive protein (CRP) was found to be positive in all the cases of septicemia. Direct and indirect Coomb's test was positive in all the cases with $\mathrm{Rh}$ incompatibility. CONCLUSION: Neonatal hyperbilirubinemia is associated with various other clinical morbidities. Causes of hyperbilirubinemia should be investigated comprehensively. ABO and Rh typing should be done along with Coombs Test, reticulocyte count and G6PD screening.

KEY WORDS: neonates, hyperbilirubinemia, hematological parameters.

INTRODUCTION: Neonatal hyperbilirubinemia is a very common condition in newborn sometimes leading to kernicterus causing brain damage. There are various conditions, both physiological and pathological leading to hyperbilirubinemia in newborn. Neonatal hyperbilirubinemia, defined as a total serum bilirubin level above $5 \mathrm{mg}$ per $\mathrm{dL}$ ( $86 \mu$ mol per L), is a frequently encountered problem in developed as well as developing countries. Although up to 60 percent of term newborns have clinical jaundice in the first week of life, few have significant underlying disease. ${ }^{1}$ It is very important for pathologists and pediatricians to differentiate the physiological and pathological causes of hyperbilirubinemia. Treatment is 
dependent upon the amount of serum bilirubin and various other laboratory investigations. So there is very important role of the pathologist in this condition to classify the neonatal hyperbilirubinemia.

The most common cause of neonatal hyperbilirubinemia in India is physiological jaundice. Various other conditions in decreasing order are preterm infant, blood group incompatibility, Neonatal septicemia, G-6PD deficiency, cephalhematoma, drug induced, RBC membrane disorders and many others.

Though the history and clinical presentation of the newborn plays a major role, the laboratory plays an important role in diagnosing the cause of hemolysis in is also helpful in diagnosing antenatally by amniocentesis and other recent available modality thereby preventing the hemolytic sequel in newborn. There are various modalities of investigations e.g. Direct and indirect coomb's test, Blood group, G-6PD deficiency, reticulocyte count by which we can reach at diagnosis. Thus laboratory workup is very important for diagnosis and prevention of neonatal hyperbilirubinemia in newborn. With this background present study was conducted to study the laboratory profile among infants with neonatal hyperbilirubinemia admitted to the hospital.

\section{OBJECTIVES:}

1. To study different causes of neonatal hyperbilirubinemia

2. To study laboratory profile of neonatal hyperbilirubunemia

MATERIAL AND METHODS: A prospective cross sectional study on neonatal hyperbilirubinemia was conducted at one of the teaching institutes of Ahmedabad. Infants admitted with significant neonatal jaundice in first week of life are included in the study. Significant Jaundice was defined as total serum bilirubin exceeding $15 \mathrm{mg} / \mathrm{dl}$ or even between 5 $\mathrm{mg} / \mathrm{dl}$ and $15 \mathrm{mg} / \mathrm{dl}$ within 24 hour of birth or the same persisting beyond one week of life. Total 63 such cases of newborn were admitted during the study period of August 2007 to October2008.Written informed consent were taken from the guardian of neonates. Detailed history of baby and mother was taken. Following investigations were done in all cases.

BLOOD GROUP (ABO/RH) OF MOTHER, FATHER AND BABY: The blood grouping was done by using known antisera with slide and tube methods

SERUM BILIRUBIN ESTIMATION OF BABY: It has been done on auto analyzer by Diazo method of Pearlman and lee.

COMPLETE BLOOD COUNT WITH PERIPHERAL SMEAR EXAMINATION: It included haemoglobin, total count, different count, band cells, peripheral smear examination and reticulocyte count.

\section{DIRECT AND INDIRECT COOMB'S TEST OF BABY AND MOTHER RESPECTIVELY}

RETICULOCYTE COUNT: Reticulocytes count has been done by stain -Briliant cresyl blue.

TEST FOR G-6-PD DEFICIENCY: Test for G-6-PD deficiency has been carried out by using SPAN Diagnostic Reagent Kit from the red cell hemolysate.

C-REACTIVE PROTEIN OF BABY: has been carried out by Latex agglutination method Data was entered and analyzed by using appropriate statistical software. $t$ test was used as a test of significance to find out the probability value.

RESULTS AND OBSERVATION: The present study includes 63 cases of newborn admitted in one of the tertiary care institutes. Various laboratory investigations of neonatal jaundice were 
carried out. Out of 63 neonates, almost two thirds (63.5\%) were 2 to 3 days old. Mean age of the neonates was 2.97 days with standard deviation of 1.2 days. 37(58.7\%) were male while 26(41.3\%) were females. Percentage of Pre-term babies was 30.1. Neonates having low birth weight were 17(26.9\%). (Table 1) Physiological jaundice constituted (40) 62\% cases of Neonatal hyperbilirubinemia. ABO incompatibility was the commonest cause of pathological jaundice and Septicemia is second commonest cause of pathological jaundice. (Table 2) Among half of the cases $(33,52.4 \%)$ range of serum total bilirubun was found between 15 and 19.9 $\mathrm{mg} / \mathrm{dl}$. 5(7.9\%) were having the serum total bilirubin more than $25 \mathrm{mg} / \mathrm{dl}$.(Figure 1) Hemoglobin level was lowest (12.1 gm \%) in Rh incompatibility. Highest level of serum bilirubin was found in Rh Incompatibility whereas highest level of reticulocytes was noted in G-6PD Deficiency. Pre-term and low birth weight babies were having higher levels of serum total bilirubin but the difference was not significant $(\mathrm{P}>0.05$ ) (Table 3) The rise in serum bilirubin level was found to be more in pathological jaundice as compare to physiological jaundice. Difference was significant statistically with $p$ value of $<0.05$. (Table 4) Direct Coomb's test and Indirect Coomb's test were found to be positive in all case in Rh incompatibility while they were positive in $77 \%$ of cases in ABO incompatibility. (Table 5) In cases of septicemia CRP was found to be positive in $100 \%$ of cases. CRP was found to be positive in a few cases of $A B O$ incompatibility (22.2\%) and physiological jaundice (5\%). (Table 6)

DISCUSSION: Study included 63 cases of Neonatal hyperbilirubinemia cases. Mean age of the neonates was $2.97 \pm 1.2$ days. Among them 37(58.7\%) were male while 26(41.3\%) were females. In the study of Choudhury Habibur Rasul ${ }^{2}$ male-to-female ratio among the neonatal jaundice cases was 1.3:1 and mean age at the appearance of jaundice was $4.5 \pm 2.3$ days. Neonatal hyperbilirubinemia was more common in male babies as compared to female babies in two different studies done by Mantani et al ${ }^{3}(62 \%$ vs. $38 \%)$ and Sharma et al ${ }^{4}(1.3: 1)$

In present study, percentage of Pre-term ( $<37$ weeks) babies was 30.1 and neonates having low birth weight $\left(<2.5 \mathrm{~kg}\right.$ ) were $17(26.9 \%)$. In the study of Nepal D et al ${ }^{5} \mathrm{LBW}$ babies constituted 19.2\%. Where as in the study of Choudhury Habibur Rasul ${ }^{2} 42 \%$ patients with neonatal jaundice had low birth weight and $37 \%$ were preterm.

In our study out of $63,40(62 \%)$ cases were diagnosed as having physiological jaundice by while others were having ABO incompatibility (15\%), Rh incompatibility(8\%), septicemia(12\%) and G-6 PD deficiency(3\%). In the study of Nepal D et al ${ }^{5}$ they noted that clinical sepsis as defined by WHO criteria was found in $86.3 \%$ of babies. Nearly $1 / 3$ rd $(32.9 \%)$ babies were $\mathrm{ABO}$ incompatible and $4.1 \%$ babies were Rh incompatible. Choudhury Habibur Rasul et $\mathrm{al}^{2}$ mentioned that Physiological jaundice was most common and was diagnosed in 114(26.7\%) cases. In their study Prematurity (20.9\%) and sepsis $\quad$ (17.6\%) were also major causes of jaundice. C. N. Onyearugha ${ }^{6}$ concluded in their study that septicaemia followed by prematurity were the leading aetiological factors of neonatal jaundice. Joshi et al $^{7}$ reported that in Septicemia, ABO incompatibility, Rh incompatibility were observed in 36.36\%, 31.8\%, $4.54 \%$ cases of neonatal jaundice respectively.G-6 PD deficiency was there in 3 percent of cases in present study. Singhal et al reported almost similar finding (G-6 PD deficiency in 5\% of cases) in their study. ${ }^{8}$

In present study mean $\mathrm{Hb}$ level was $14.2+/-1.7 \mathrm{gm} / \mathrm{dl}$ with range of $10-18 \mathrm{gm} / \mathrm{dl}$. Similar findings were noted in the study carried out by Joshi et al 7 . The findings of their study showed Mean Hb level of 13.87+/- 3.59gm/dl with a range of 8- $19.4 \mathrm{gm} / \mathrm{dl}$.

Journal of Evolution of Medical and Dental Sciences/Volume1/ Issue3/July-Sept 2012 Page 205 
In any infant, 24 hours old any jaundice is considered pathologic and requires evaluation. This evaluation should minimally include a serum bilirubin and workup for hemolytic disease. Guidelines for therapy depend upon the serum concentration of bilirubin and the patient's age. Also serum bilirubin is most important investigation to judge severity and management of patient. In present study serum bilirubin was highest in $\mathrm{ABO}$ incompatibility and $\mathrm{Rh}$ Incompatibility. Among half of the cases (52.4\%) range of serum total bilirubun was found between 15 and $19.9 \mathrm{mg} / \mathrm{dl}$. Same results were observed in the study of Nepal D et al ${ }^{5}$. They mentioned that maximum number (67.1\%) of infants' peak serum bilirubin fell in the range of $15-19.9 \mathrm{mg} / \mathrm{dl}$.

DCT and ICT were positive in $100 \%$ cases of Rh incompatibility while in ABO incompatibility they were found to be positive in $77 \%$ of cases. The reason for this difference may have been that " $\mathrm{A}$ " and " $\mathrm{B}$ " antigens are weaker antigens and the distance between $\mathrm{a} / \mathrm{b}$ antigen sites on the fetal red cells as compared to adult red cells is more. In all cases of septicemia CRP was positive in present study. It is an acute phase reactant; is synthesized by the liver and it becomes positive after any inflammation. It is a very reliable indicator.

To conclude, most of the cases were having idiopathic jaundice although septicemia and ABO-Rh incompatibility were not exceptional. Peak serum bilirubin levels were found to be more among the pathological jaundice. Also prematurity and low birth weight were having higher levels of s. bilirubin. Special care must be given to them in order to avoid future complications of hyperbilirubinemia

ACKNOWLEDGEMENT: We are thankful to parents/guardians of all the neonates for their cooperation while carrying out the study.

TABLE-1 Demographic profile of Neonatal Hyperbilirubinemia cases

\begin{tabular}{|l|l|l|}
\hline Variables & No. & Percentage \\
\hline Age (in Days) & & \\
\hline 1 & 5 & 7.9 \\
\hline 2 & 19 & 30.2 \\
\hline 3 & 21 & 33.3 \\
\hline 4 & 13 & 20.6 \\
\hline 5 & 2 & 3.2 \\
\hline 6 & 2 & 3.2 \\
\hline 7 & 1 & 1.6 \\
\hline Sex & & \\
\hline Female & 26 & 41.3 \\
\hline Male & 37 & 58.7 \\
\hline Gestational Age & & \\
\hline Pre-Term & 19 & 30.1 \\
\hline Term & 44 & 69.9 \\
\hline Birth weight & & \\
\hline Normal & 46 & 73.1 \\
\hline LBW & 17 & 26.9 \\
\hline
\end{tabular}

TABLE-2 Etiology wise distribution of Neonatal Hyperbilirubinemia

\begin{tabular}{|l|l|l|}
\hline Etiology & No. Of Cases & Percentage \\
\hline Physiological Jaundice & 40 & 62 \\
\hline Suspected ABO Incompatibility & 09 & 15 \\
\hline
\end{tabular}

Journal of Evolution of Medical and Dental Sciences/Volume1/ Issue3/July-Sept 2012 Page 206 
ORIGINAL ARTICLE

\begin{tabular}{|l|l|l|}
\hline Septicemia & 08 & 12 \\
\hline Rh Incompatibility & 04 & 08 \\
\hline G-6PD deficiency & 02 & 03 \\
\hline Total & 63 & 100 \\
\hline
\end{tabular}

TABLE-3 Mean level of Hemoglobin, Serum bilirubin and Reticulocyte count in Neonatal hyperbilirubinemia

\begin{tabular}{|l|l|l|l|}
\hline Etiology & $\begin{array}{l}\text { Mean Hb } \\
\text { (gm \%) }\end{array}$ & $\begin{array}{l}\text { Mean serum } \\
\text { Bilirubin } \\
\text { (mg/d) }\end{array}$ & $\begin{array}{l}\text { Mean } \\
\text { Reticulocyte } \\
\text { count (\%) }\end{array}$ \\
\hline $\begin{array}{l}\text { Physiological } \\
\text { Jaundice }\end{array}$ & 14.8 & 15.5 & 2.53 \\
\hline $\begin{array}{l}\text { ABO } \\
\text { Incompatibility }\end{array}$ & 14.2 & 19.6 & 3.77 \\
\hline Rh Incompatibility & 12.1 & 18 & 5.5 \\
\hline Septicemia & 12.6 & 20.2 & 4.6 \\
\hline G-6PD deficiency & 13.7 & 19.2 & 6 \\
\hline
\end{tabular}

TABLE-4 Mean Serum bilirubin value: physiological Vs Pathological Neonatal Jaundice

\begin{tabular}{|l|c|c|c|}
\hline Neonatal Jaundice & Mean Level of S. Bilirubin(mg/dl) & t- value & P value \\
\hline Physiological(n=40) & $15.4 \pm 2.8$ & & \\
\hline Pathological(n=23) & $19.5 \pm 4.1$ & 4.6 & $<0.05$ \\
\hline
\end{tabular}

TABLE-5 Result of Coomb's test in Rh and ABO incompatibility

\begin{tabular}{|l|l|l|l|l|l|l|}
\hline \multicolumn{2}{|l|}{} & \multicolumn{2}{l|}{ DCT } & ICT & \\
\cline { 2 - 7 } & +ve & -ve & Total & +ve & -ve & Total \\
\hline $\begin{array}{l}\text { Rh } \\
\text { incompatibility }\end{array}$ & $4(100 \%)$ & 0 & 4 & $4(100 \%)$ & 0 & 4 \\
\hline $\begin{array}{l}\text { ABO } \\
\text { incompatibility }\end{array}$ & $7(77 \%)$ & $2(23 \%)$ & 9 & $7(77 \%)$ & $2(23 \%)$ & 9 \\
\hline
\end{tabular}

TABLE-6 Result of C - reactive protein in Neonatal Septicemia

\begin{tabular}{|l|l|l|}
\hline Etiology & $\begin{array}{l}\text { CRP positive } \\
\text { n(\%) }\end{array}$ & Total No. of Cases \\
\hline Septicemia & $08(100)$ & 08 \\
\hline $\begin{array}{l}\text { Physiological } \\
\text { Jaundice }\end{array}$ & $02(5)$ & 40 \\
\hline $\begin{array}{l}\text { ABO } \\
\text { Incompatibility }\end{array}$ & $02(22.2)$ & 09 \\
\hline Rh Incompatibility & $00(00)$ & 04 \\
\hline G-6PD deficiency & $00(00)$ & 02 \\
\hline
\end{tabular}

Journal of Evolution of Medical and Dental Sciences/Volume1/ Issue3/July-Sept 2012 Page 207 
Figure: 1 Level of serum total bilirubin $(\mathrm{mg} / \mathrm{dl})$ among the neonatal jaundice cases

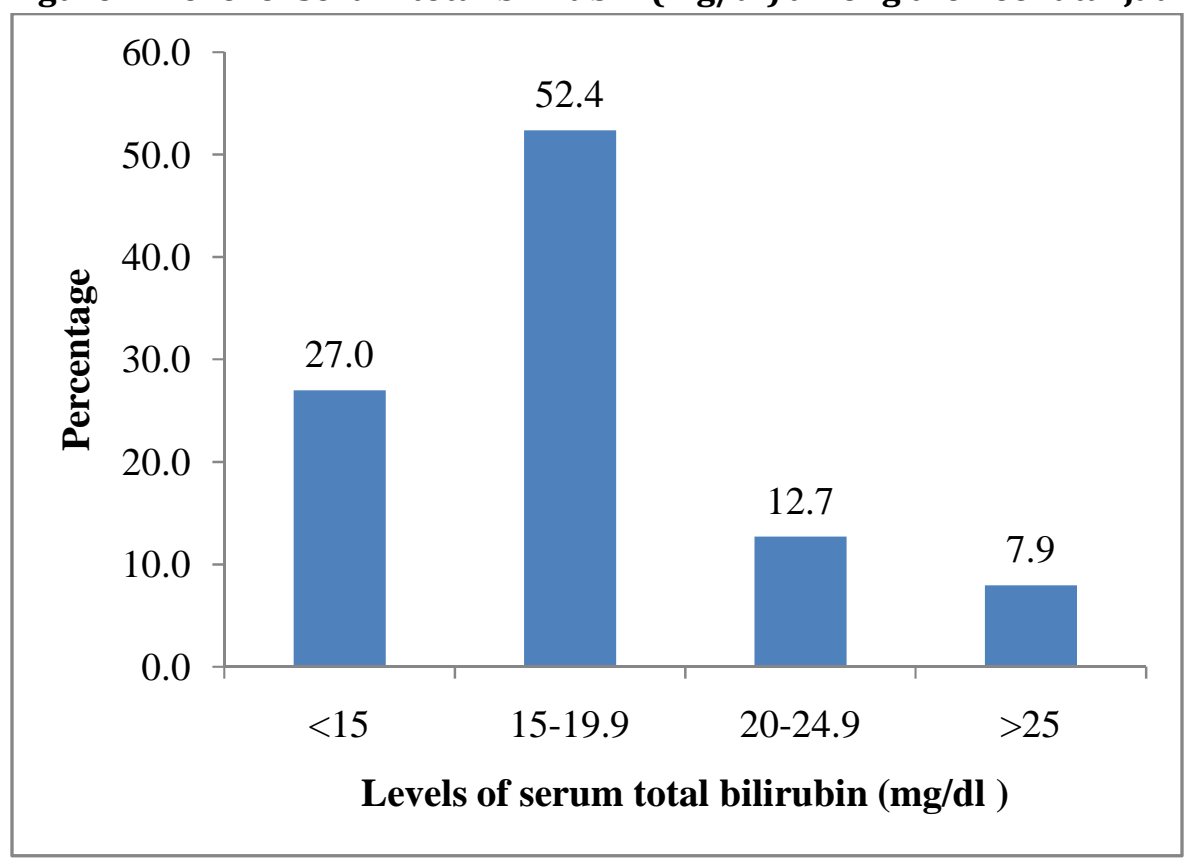

\section{REFERENCES:}

1. American Academy of Pediatrics. Report of the committee on infectious disease (Redbook).Elk Grove Village III: AAP, 24th Ed.1997, p5054.

2. Choudhury Habibur Rasul, Md Abul Hasan, Farhana Yasmin. Outcome of Neonatal Hyperbilirubinemia in a Tertiary Care Hospital in Bangladesh Malaysian J Med Sci. AprJun 2010; 17(2): 40-44

3. Mantani M, Patel A, Renge R, Kulkarni H. Prognostic value of direct bilirubin in Neonatal Hyperbilirubinemia. Indian J Pediatr 2007; 79: 819-22.

4. Sharma P, Chhangani NP, Meena KR, Jora R, Sharma N, Gupta BD. Brainstem Evoked Response Audiometry (BAER) in neonates with hyperbilirubinemia. Indian J Pediatr 2006; 73: 413-16.

5. Nepal D, Banstola D, Dhakal AK ,Mishra U, Mahaseth C Clinico-Laboratory Profile and Immediate Outcomes of Hyperbilirubinemic Babies Admitted in Kanti Children Hospital Journal of Nepal Paediatric Society; January-June, 2010/Vol 30/Issue 1

6. C. N. Onyearugha, B. N. Onyire and H. A. A. Ugboma. Neonatal jaundice: Prevalence and associated factors as seen in Federal Medical Centre Abakaliki, Southeast Nigeria. Journal of Clinical Medicine and Research Vol. 3(3) pp. 40-45, March 2011

7. Joshi BD, Singh R, Mahato D and Prasad R. Clinico-Laboratory Profile of Neonatal Hyper-bilirubinemia in Term Babies at B.P. Koirala Institute of Health Sciences (BPKIHS), Dharan, Nepal. Journal of Nepal Health Research Council Vol. 2 No. 2 October 2004

8. Singhal PK, Singh M, Paul VK, Deorari AK, Ghorpade MG. Spectrum of neonatal hyperbilirubinemia: An analysis of 454 cases. Indian Pediatr 1992; 29: 319-325. 